\title{
Centrilobular emphysema and panlobular emphysema: two different diseases ${ }^{1}$
}

\author{
A. E. ANDERSON, JR. and ALVAN G. FORAKER \\ Research Laboratory, Baptist Memorial Hospital, 800 Prudential Drive, \\ Jacksonville, Florida 32207, U.S.A.
}

\begin{abstract}
Anderson, A. E., and Foraker, A. G. (1973). Thorax, 28, 547-550. Centrilobular emphysema and panlobular emphysema: two different diseases. Twenty-one cases of centrilobular emphysema and 19 cases of panlobular emphysema, previously so designated according to recommended criteria, were reassessed for differences in zonal distribution within lungs through systematic sampling and statistical comparisons. Characteristic distribution profiles were defined for the two forms of disease. Centrilobular emphysema appeared to be mainly a disease of the upper lobe and the apices within the upper and lower lobes. In contrast, panlobular emphysema was a more or less diffuse process within lobes and lungs with mild preferential involvement of the lower lobe. These regional trends coupled with the typical appearance of individual lesions within lobules are considered to provide strong support for the contention that centrilobular emphysema and panlobular emphysema are morphologically distinct entities. Probable reasons for difficulties in differentiating some examples of centrilobular and panlobular emphysema are given. The need for further clarification of associated and background factors is stressed.
\end{abstract}

Two major types of disruptive pulmonary emphysema were differentiated in a general population in 1957 and designated centrilobular and generalized emphysema (Leopold and Gough, 1957). In an ensuing evolution of semantics, the respective terms centrilobular or centriacinar and panlobular or panacinar were applied eventually to the two conditions (Ciba Guest Symposium, 1959; American Thoracic Society, 1962). Centrilobular emphysema has been characterized as beginning in and around the centres of the pulmonary lobules whereas panlobular emphysema develops in a more or less generalized or uniform fashion within lobules, lobes or even entire lungs. A predilection of centrilobular emphysema for the lung apices has also been noted (Thurlbeck, 1963). The medical community has not been unanimous in accepting this concept of two basic forms of disease; typical reservations were expressed in a recent article (Mitchell et al., 1970). The purpose of the present study is to examine this problem by systematic sampling of lungs for differences in the distribution of these two types of emphysema.

IThis work was supported by research grants from the Florida Tuberculosis and Respiratory Disease Association and the Northeast Florida Heart Association. Paper read at the Ninth International Florida Heart Association. Paper read at the Ninth International 5 September, 1972.

\section{MATERIALS AND METHODS}

From a large store of paper-mounted whole lung sections already graded for degree and type of pulmonary emphysema during a series of previous investigations by various members of our group, 21 cases of centrilobular emphysema and 19 cases of panlobular emphysema were chosen for this analysis. The two groups of cases were of comparable severity. Causes of death included emphysema as well as other diseases common to a general hospital population. Details regarding the method of lung preparation (Gough and Wentworth, 1960) and general approach to sample selection and lung assessment are available elsewhere (Anderson, Hernandez, Holmes, and Foraker, 1966). Single parahilar macrosections were chosen, since it was previously observed in our study material that this plane did not show statistically important deviations in extent and type of emphysema from the mid-sagittal level and the lateral aspect of the lung (Anderson et al., 1966). The grading system employed previously gives an indication of severity, ranging on a scale from 0 to 6 , and a visual impression of the type of emphysema present without reference to extent.

The only criterion for admission to either group was a previous designation of more or less pure centrilobular or panlobular emphysema in accordance with recommended criteria (Leopold and Gough, 1957; Ciba Guest Symposium, 1959; American Thoracic 


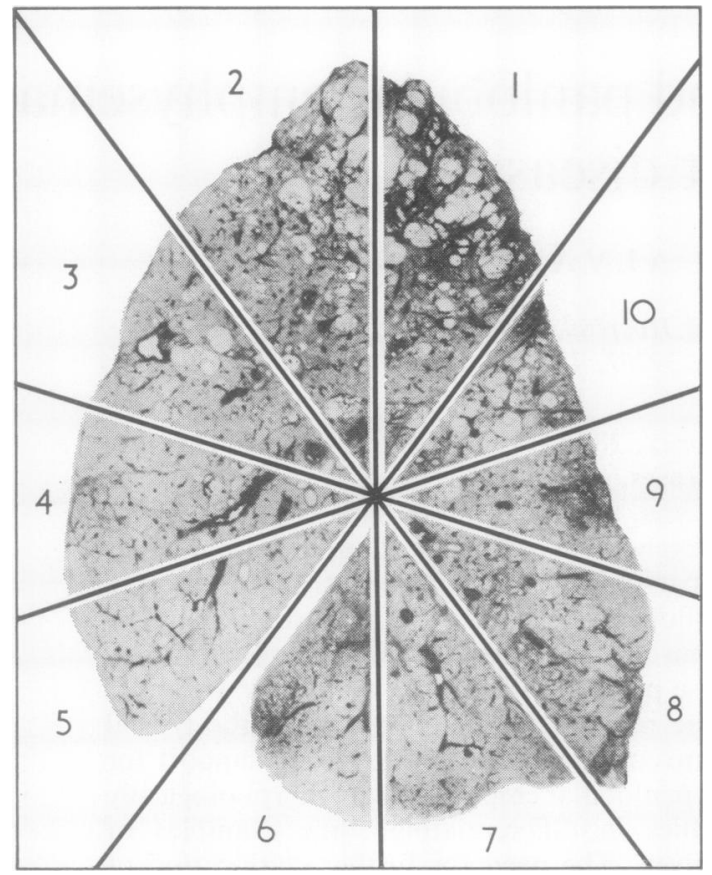

FIG. 1. Transparent plastic Ryder grid divided into 10 equal, wedge-shaped, radiating segments, placed with its mid point at the mid point of the greater fissure and with the diameter between zones 1 and 10 lying over the greater fissure of a paper-mounted whole-lung section. When numbered counterclock-wise, with the lung in this position, zones 1 to 5 correspond to upper lobe, zones 6 to 10 to lower lobe, zones 1 and 2 to apex of upper lobe, and zones 9 and 10 to apex of lower lobe. Grid zones numbered clockwise correspond to same lung areas for lung specimen mounted in the opposite direction.

Society, 1962). These lungs were then regraded for severity and distribution of emphysema with a transparent Ryder grid (Ryder, Thurlbeck, and Gough, 1969). When properly positioned over a paper-mounted lung section a Ryder grid divides a specimen into 10 equal, wedge-shaped, radiating segments, corresponding to the zones shown in Figure 1. Using such a grid, emphysema was scored as either $0,1,2$, or 3 in each section of the grid. These corresponded respectively to the standards of 'no', 'mild', 'moderate', and 'severe' disease of Ryder and associates, which have been made available to interested workers (Ryder et al., 1969; Thurlbeck et al., 1970). The sum of the scores from the separate zones of a given lung constitutes the emphysema grade for that lung according to the original Ryder system. However, we utilized the mean of these zonal scores with standard deviations, since this approach seemed to satisfy better the statistical needs of the present study. Data so obtained from the two groups of previously designated panlobular and centrilobular emphysema were then statistically assessed and compared for patterns of distribution by $\frac{\bar{O}}{\bar{\omega}}$ zone throughout the entire lung.

\section{RESULTS}

The general characteristics of the subjects of this study are summarized in Table $I$. The severity of both types of emphysema varied from mild to $\vec{\omega}$ extreme; however, the mean degree of disease was the same for the two groups, i.e., 1.5. All the $\vec{x}$ patients with centrilobular emphysema were cigarette smokers and all but two were men. o Smoking histories were available on 15 individuals or with panlobular emphysema; eight of these were $\underset{V}{ }$ cigarette smokers. Of the total group of 19 patients 음 with panlobular emphysema, 11 were men.

T A B L E I

GENERAL CHARACTERISTICS OF 21 CASES OF CENTRILOBULAR AND 19 CASES OF PANLOBULAR EMPHYSEMA

\begin{tabular}{|c|c|c|c|c|c|c|}
\hline \multirow{2}{*}{\multicolumn{2}{|c|}{ Age Sex }} & \multicolumn{2}{|c|}{ Centrilobular } & \multirow[b]{2}{*}{ Age Sex } & \multicolumn{2}{|c|}{ Panlobular } \\
\hline & & $\begin{array}{c}\text { Lung } \\
\text { Grade }^{1}\end{array}$ & $\begin{array}{l}\text { Cigarette } \\
\text { Smoker }\end{array}$ & & $\underset{\text { Grade }^{1}}{\text { Lung }}$ & $\begin{array}{l}\text { Cigarette } \\
\text { Smoker }\end{array}$ \\
\hline $\begin{array}{l}74 \\
61 \\
76 \\
72 \\
63 \\
53 \\
73 \\
68 \\
70 \\
73 \\
73 \\
66 \\
69 \\
71 \\
68 \\
68 \\
65 \\
69 \\
76 \\
72 \\
52\end{array}$ & $\begin{array}{l}\mathbf{M} \\
\mathbf{M} \\
\mathbf{M} \\
\mathbf{M} \\
\mathbf{M} \\
\mathbf{M} \\
\mathbf{M} \\
\mathbf{M} \\
\mathbf{M} \\
\mathbf{M} \\
\mathbf{M} \\
\mathbf{M} \\
\mathbf{M} \\
\mathbf{M} \\
\mathbf{M} \\
\mathbf{M} \\
\mathbf{F} \\
\mathbf{M} \\
\mathbf{M} \\
\mathbf{M} \\
\mathbf{F}\end{array}$ & $\begin{array}{l}1 \cdot 6 \\
0.9 \\
2 \cdot 3 \\
2.0 \\
2 \cdot 2 \\
1.2 \\
1 \cdot 4 \\
1 \cdot 3 \\
1 \cdot 7 \\
1.0 \\
1 \cdot 1 \\
2 \cdot 1 \\
1 \cdot 5 \\
0.8 \\
1.2 \\
2.4 \\
1.9 \\
1.2 \\
1.5 \\
2.0 \\
0.7\end{array}$ & $\begin{array}{l}+ \\
+ \\
+ \\
+ \\
+ \\
+ \\
+ \\
+ \\
+ \\
+ \\
+ \\
+ \\
+ \\
+ \\
+ \\
+ \\
+ \\
+ \\
+ \\
+ \\
+\end{array}$ & $\begin{array}{ll}74 & \mathrm{~F} \\
75 & \mathrm{~F} \\
64 & \mathrm{~F} \\
87 & \mathrm{~F} \\
60 & \mathrm{M} \\
78 & \mathrm{M} \\
76 & \mathrm{~F} \\
88 & \mathrm{~F} \\
59 & \mathrm{M} \\
64 & \mathrm{M} \\
64 & \mathrm{M} \\
68 & \mathrm{M} \\
51 & \mathrm{M} \\
44 & \mathrm{M} \\
93 & \mathrm{M} \\
67 & \mathrm{M} \\
86 & \mathrm{~F} \\
66 & \mathrm{M} \\
52 & \mathrm{~F}\end{array}$ & $\begin{array}{l}2.4 \\
0.7 \\
0.6 \\
0.7 \\
1.2 \\
3.0 \\
0.6 \\
0.8 \\
1.2 \\
1.8 \\
0.8 \\
0.7 \\
1.0 \\
1.4 \\
2.4 \\
2.5 \\
1.7 \\
1.9 \\
2.3\end{array}$ & $\begin{array}{l} \pm \\
= \\
= \\
\overline{+} \\
\pm \\
\overline{+} \\
+ \\
+ \\
+ \\
? \\
+ \\
+ \\
+ \\
\frac{+}{?} \\
?\end{array}$ \\
\hline
\end{tabular}

${ }^{1}$ Mean of 10 zones per lung with Ryder grid and standards

The distribution profiles of the centrilobular and panlobular forms of emphysema are demonstrated graphically (Fig. 2). Mean degrees of the two forms of emphysema for different lung locations are compared statistically in Table II. Differences are of immediately apparent. Centrilobular emphysema $\mathrm{N}$ tended to fluctuate considerably in severity from $N$ area to area within the lungs and this was reflected in preferential involvement of certain zones. Thus, there was significantly more centrilobular emphy- $\stackrel{\odot}{\subset}$

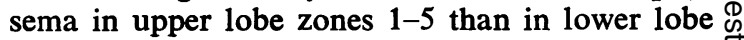
zones 6-10. Centrilobular disease also was substantially more prevalent in the upper lobe apical $\frac{0}{0}$ zones 1 and 2 than in the remainder of the upper $\stackrel{\vec{D}}{\circ}$ lobe zones and also more common in the lower $\frac{?}{\mathbb{D}}$ lobe apical zones 9 and 10 than in the other lower $\varrho$ lobe zones. In contrast, panlobular emphysema showed a much more even distribution in the lungs, 8 
but the lower lobe zones 6-10 were slightly more affected than the upper lobe zones $1-5$. No statistically significant differences were obtained for panlobular emphysema between different zones of the lung lobes.

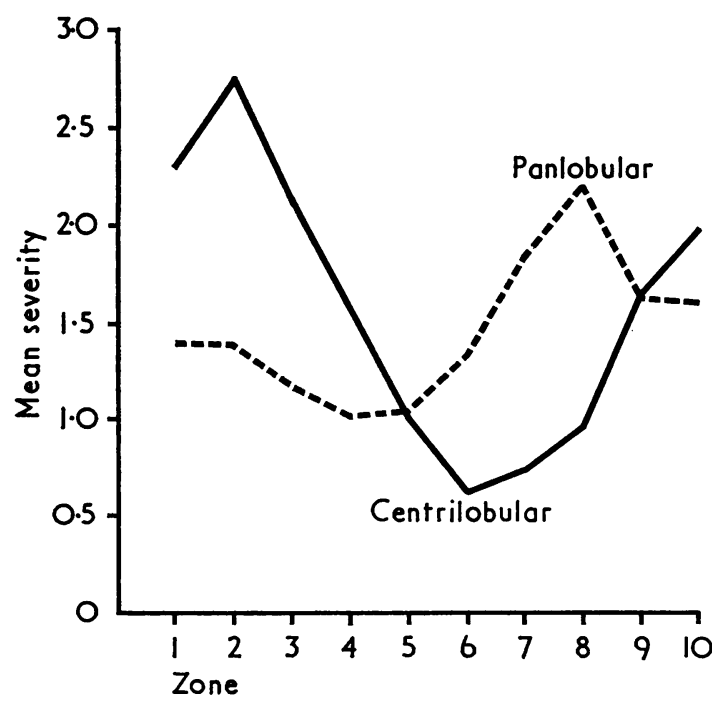

FIG. 2. Mean severity by lung zones (see Fig. 1) for 21 cases of centrilobular emphysema and 19 cases of panlobular emphysema.

T A B L E I I

PAIRED COMPARISONS OF MEAN SEVERITY BY LOCATION FOR ALL CASES OF PANLOBULAR AND CENTRILOBULAR EMPHYSEMA

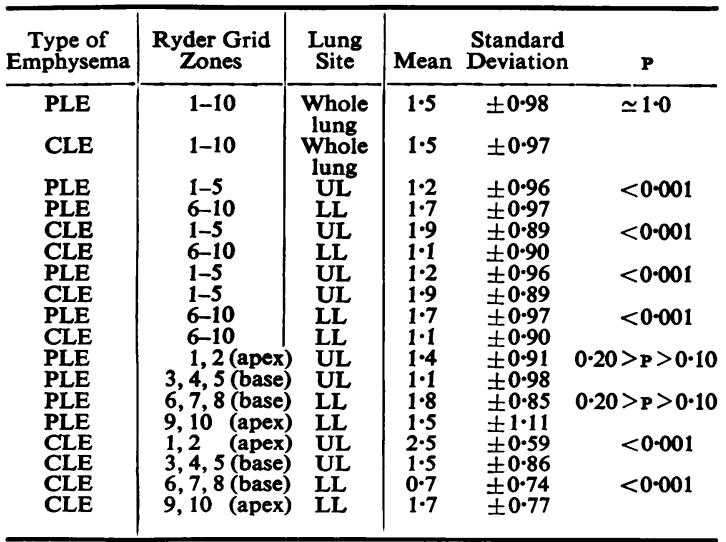

Consideration of means and standard deviations of emphysema scores for the 10 zones provides another index of distribution of centrilobular and panlobular emphysema within the lungs. This type of analysis is demonstrated graphically (Fig. 3). If

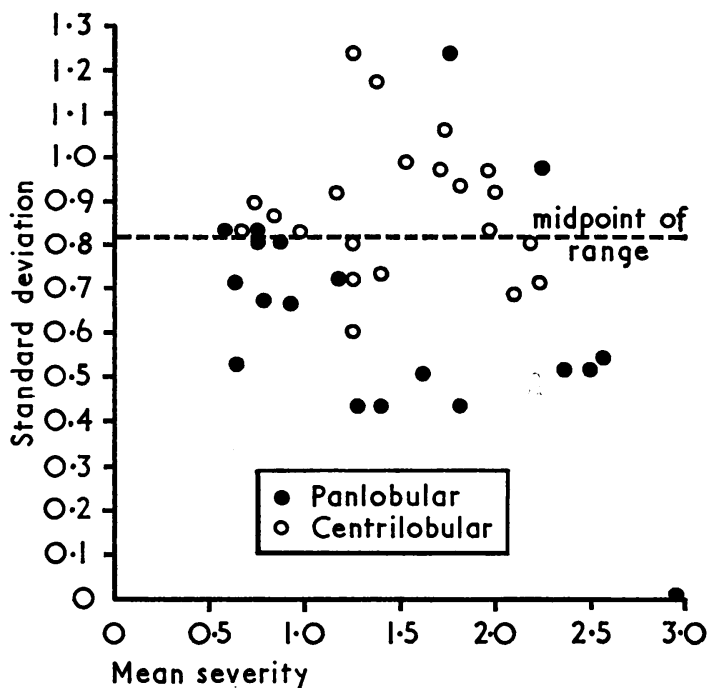

FIG. 3. Distribution of mean severity of emphysema per lung by standard deviation for 21 cases of centrilobular and 19 cases of panlobular emphysema.

the mid point in the range of standard deviations $(0 \cdot 81)$ is used as a reference point for all cases, it will be seen that centrilobular emphysema was characterized by a relatively high degree of variability with respect to zonal distribution or scatter $\left(0.005>p>0.001\right.$ by $\chi^{2}$ test). The comparatively low standard deviations of the panlobular cases suggest much greater homogeneity. Despite these trends it is of interest that the distribution of centrilobular disease more closely approximated that of panlobular emphysema with higher grades of disease ( $P>0.10$ by $F$ test comparing distribution of panlobular and centrilobular disease for mean severity $1 \cdot 6-3 \cdot 0$ ). This probably has had a bearing on difficulties in distinguishing between the two forms of emphysema and is discussed in this context later.

\section{DISCUSS:ON}

Most previous descriptions of the morphology of centrilobular and panlobular emphysema were based largely on visual impressions of the relations of these lesions to pulmonary lobules and acini (Leopold and Gough, 1957; Ciba Guest Symposium, 1959; American Thoracic Society, 1962). In the present analysis, characteristic macroscopic patterns of distribution were defined with respect to the whole lung through systematic sampling and statistical comparisons of different lung zones. These findings are in general agreement with those of Thurlbeck (1963). 
As mentioned earlier, some workers have expressed serious reservations concerning the distinct natures of centrilobular emphysema and panlobular emphysema (Mitchell et al., 1970). Several factors have contributed to this. Centrilobular and panlobular emphysema are highly prevalent in the general population and thus commonly co-exist in all stages of severity in the same individual. When possible, we have found it convenient to classify these lungs with both forms of disease as mainly centrilobular or mainly panlobular for statistical purposes. Another circumstance leading to difficulties in diagnosis is the advanced state of disease in some specimens coming to necropsy. This was reflected statistically in this study by the finding of similar distribution profiles for centrilobular and panlobular emphysema when severe disease was present. To quote Liebow (1968), inspection of such lung '. . . may be merely sifting the ashes of fires long dead'. Study of other vital organs with end stage disease, such as the kidney, has been fraught with similar difficulties. This, however, in no way minimizes the essentially separate natures of the different processes which lead to near total organ destruction. Even in the presence of advanced emphysema, intermediate and even slight lesions demonstrating the basic patterns can often be found on careful search.

Although there seems to be little reasonable doubt that centrilobular emphysema and panlobular emphysema are morphologically distinct, it may be argued that their differentiation has no clinical relevance. However, some clinical differences have been observed. Thus, centrilobular emphysema has been associated closely with smoking (Anderson et al., 1966; Gough, 1968; Ryder, Dunnill, and Anderson, 1971) whereas panlobular emphysema has been observed with random frequency in smokers and non-smokers (Anderson et al., 1966). The findings in the present study are in keeping with these earlier reports. Emphysema with a panlobular distribution has also been associated with ageing in non-smokers (Anderson, Furlaneto, and Foraker, 1970) and with deficiency of serum $\alpha_{1}$ antitrypsin (Guenter et al., 1968).

\section{REFERENCES}

American Thoracic Society (1962). Definitions and classifica- $\frac{\partial}{\top}$ tion of chronic bronchitis, asthma, and pulmonarye emphysema. American Review of Respiratory Diseases, $85,762$.

Anderson, A. E., Jr., Furlaneto, J. A., and Foraker, A. G.루 (1970). Bronchopulmonary derangements in non $\overrightarrow{-}$ smokers. American Review of Respiratory Diseases, 101, $\vec{\omega}$ 518.

Hernandez, J. A., Holmes, W. L., and Foraker, A. G. $\vec{x}$ (1966). Pulmonary emphysema. Archives of Environ- $-_{\infty}$ mental Health, 12, 569.

Ciba Guest Symposium (1959). Terminology, definitions, and classification of chronic pulmonary emphysema and $\underset{V}{ }$ related conditions. Thorax, 14, 286.

Gough, J. (1968). The pathogenesis of emphysema. In The $\rightarrow$ Lung, edited by A. A. Liebow, p. 109. Williamses and Wilkins, Baltimore.

- and Wentworth, J. E. (1960). Thin sections of entire organs mounted on paper. In Recent Advances in Pathology, edited by C. V. Harrison, 7th ed., p. $80 . \bar{\Phi}$ Churchill, London.

Guenter, C. A., Welch, M. H., Russell, T. R., Hyde, R. M. $\vec{\theta}$ and Hammarsten, J. F. (1968). The pattern of lungw disease associated with alpha-1 antitrypsin deficiency. Archives of Internal Medicine, 122, 254.

Leopold, J. G., and Gough, J. (1957). The centrilobular form of hypertrophic emphysema and its relation to chronico bronchitis. Thorax, 12, 219.

Liebow, A. A. (1968). Epilogue. In The Lung, edited byळ A. A. Liebow, p. 366. Williams and Wilkins, Baltimore. $\overrightarrow{\bar{O}}$

Mitchell, R. S., Silvers, G. W., Goodman, N., Dart, Gladys,, and Maisel, J. C. (1970). Are centrilobular emphysema? and panlobular emphysema two different diseases Human Pathology, 1, 433.

Ryder, R. C., Dunnill, M. S., and Anderson, J. A. (1971). AŌ quantitative study of bronchial mucous gland volume, emphysema and smoking in a necropsy population Journal of Pathology, 104, 59.

- Thurlbeck, W. M., and Gough, J. (1969). A study of interobserver variation in the assessment of the amount of pulmonary emphysema in paper-mounted whole lung sections. American Review of Respiratory Diseases, 99, 354.

Thurlbeck, W. M. (1963). The incidence of pulmonary emphysema. With observations on the relative incidence and spatial distribution of various types of emphysema. American Review of Respiratory Diseases, 87, 206.

Dunnill, M. S., Hartung, W., Heard, B. E., Hepplestonภ A. G., and Ryder, R. C. (1970). A comparison of three methods of measuring emphysema. Human Pathology 1, 215. 